\title{
EL TRIUNFO DE LA ROCALLA: EL RETABLO DE LA CAPILLA DEL COLEGIO SAGRADA FAMILIA DE SEVILLA, OBRA DE FRANCISCO DE ACOSTA "EL MAYOR"
}

\section{THE ROCAILLE VICTORY: THE CHAPEL ALTARPIECE OF THE SAGRADA FAMILIA SCHOOL IN SEVILLE, FRANCISCO DE ACOSTA EL MAYOR'S WORK}

\author{
Álvaro Recio Mir \\ Universidad de Sevilla. España \\ alvarorecio@us.es \\ Miguel A. Mariscal RodríGuez \\ IES Nervión, Sevilla. España \\ profesormiguelmariscal@gmail.com
}

\begin{abstract}
Vinculamos el retablo de la capilla del colegio Sagrada Familia de Sevilla a Francisco de Acosta "el Mayor", el cual procede del conjunto que hizo para el Carmen Calzado de Carmona entre 1770 y 1772 y que actualmente se encuentra disperso.

Palabras clave: Francisco de Acosta "el Mayor"; retablo; Sevilla; siglo XVIII; Rococó.

We link the altarpiece at Sagrada Familia School's chapel in Seville to Francisco de Acosta "el Mayor", which proceeds from the set that he built for the Carmen Calzado Convent in Carmona between 1770 and 1772 and that is dispersed nowadays.

Keywords: Francisco de Acosta "el Mayor"; altarpiece; Seville; $18^{\text {th }}$ century; Rococo.
\end{abstract}

La extraordinaria riqueza de la escuela artística hispalense, a pesar de las cuantiosas e irreparables pérdidas que ha sufrido, permite que se produzcan felices sorpresas como el descubrimiento en 2016 de una excelente escultura de San José con el Niño, obra inequívoca de Juan de Mesa, en la capilla del colegio Sagrada Familia, en la calle 
Pozo de Sevilla, de las hermanas carmelitas de Vedruna ${ }^{1}$. Tiempo habrá de analizar con detenimiento esta escultura recientemente restaurada que, entre otros muchos valores, atesora la presencia de un Niño Jesús exento, el cual creemos que puede dar claves para acabar de aquilatar el desarrollo de tan importante iconografía ${ }^{2}$.

Esta obra fue parte de la generosa dotación de la benefactora del colegio, doña Gertrudis Zuazo Zuazo ${ }^{3}$, quien además de ceder las casas sobre las que el colegio se asienta desde 1896, legó por cláusulas testamentarias fechadas en 1905 algunos otros bienes muebles ${ }^{4}$. Pero si de gran calidad es esta imagen de San José con el Niño, no lo es menos el retablo que preside la capilla del colegio y del que nos ocuparemos en esta ocasión.

Se trata de una ensambladura de virtuosa talla rococó, lo que se manifiesta de forma evidente al conservarse en blanco, es decir, nunca fue dorado ni policromado. Por desgracia, ha perdido las imágenes con las que contaba en origen, presidiendo en la actualidad el espacio central de su cuerpo un Crucificado de pequeño formato y las hornacinas de las calles laterales sendas esculturas de la Virgen del Carmen y de Santa Joaquina de Vedruna. Por su parte, en el ático, el manifestador lo ocupa una Sagrada Familia. Todas ellas son obras realizadas en serie, sin particular interés artístico. Tampoco formaba parte en origen del retablo su actual sagrario (Figura 1).

El análisis del retablo nos conduce de manera directa a distintas obras, algunas documentadas y otras atribuidas fundadamente, de Francisco de Acosta "el Mayor”, primogénito del gran artífice del rococó sevillano Cayetano de Acosta.

1 Agradecemos a la comunidad de hermanas carmelitas de Vedruna y al director del colegio, don José Antonio Ortega, la amabilidad y ayuda prestadas en la realización de este artículo.

${ }^{2}$ Sobre la imagen de San José con el Niño remitimos al artículo que Manuel Jesús Roldán publicó en el diario digital Pasión en Sevilla, con información de José Carlos Pérez Morales, http://sevilla.abc.es/pasionensevilla/actualidad/noticias/san-jose-y-el-niño-unanueva-obra-de-juan-de-mesa-93684-1460943175.html (Consultado el 9-8-2016).

${ }^{3}$ Véase sobre este personaje, en relación a la Hermandad de Jesús Nazareno de Sevilla, SÁNCHEZ FERNÁNDEZ-PALACIOS, Pablo: "Centenario de una bienhechora", Boletín de la Archicofradia de la Hermandad del Silencio, 111, 2005, pp. 6-8.

${ }^{4}$ Esta imagen de San José con el Niño fue cedida al colegio en 1905, tras la muerte de doña Gertrudis Zuazo, por su albacea don Francisco Caballero Infante. Después de la Guerra Civil, tras establecerse provisionalmente en la capilla del colegio la parroquia de San Gil, esta quiso trasladar el San José a su sede una vez rehabilitada, siendo ello impedido por el colegio, lo que ha permitido que la siga conservando hasta la actualidad. Véase MARTÍN RIEGO, Manuel: Colegio de la Sagrada Familia. Cien años de presencia Vedruna en Sevilla (1895-1995). Sevilla, 1995. Se trata de un libro no venal y corta tirada, publicado con ocasión del centenario de la fundación del colegio. Su contenido fue publicado también en forma de artículo por el mismo autor y título en Isidorianum, 8, 1995, pp. 215-282. 
En particular, la relación de esta pieza es llamativa con el conjunto de retablos que contrató Francisco de Acosta "el Mayor" para el desaparecido convento del Carmen Calzado de Carmona. En concreto, en 1770 se obligó por 26.000 reales, apareciendo como fiador su padre, a levantar el retablo mayor de la iglesia conventual, su primera obra conservada y que se encuentra en la actualidad en la capilla de la Fundación San Telmo de Sevilla, donde fue instalado a principios del siglo XX, cuando el edificio era Casa Cuna ${ }^{5}$.

En 1772 Francisco de Acosta "el Mayor", de nuevo apareciendo como fiador su padre, se comprometía a realizar dos retablos colaterales para la capilla mayor de la misma iglesia, "para concurrir por este medio al culto a Dios debido", y tasado cada uno en 15.000 reales, lo que indica un tamaño menor que el mayor aludido ${ }^{6}$ Por último, por evidentes cuestiones estilísticas, Francisco Herrera identificó de manera inequívoca como obra del mismo autor y también procedente del referido convento el retablo que actualmente preside la iglesia de San Francisco en la localidad sevillana de Fuentes de Andalucía, el cual no es referido en ninguno de los dos contratos aludidos ${ }^{7}$.

Todo indica que este retablo de la capilla del colegio Sagrada Familia de Sevilla es uno de los dos retablos colaterales contratados en 1772. Sabemos en tal sentido que la hermana superiora del colegio en 1916 solicitó al Arzobispado de Sevilla "uno de los dos retablos que existen en la iglesia del Carmen de la ciudad de Carmona"

${ }^{5}$ El referido contrato fue publicado en MIRA CABALLOS, Esteban y DE LA VILLA NOGALES, Fernando: Carmona en la Edad Moderna. Religiosidad y arte, población y emigración a América. Sevilla, 1999, pp. 133 y 134. El retablo fue dado a conocer y atribuido a Francisco de Acosta "el Mayor" en RECIO MIR, Álvaro: "El retablo rococó", en HALCÓN, Fátima, HERRERA, Francisco y RECIO, Álvaro: El retablo barroco sevillano. Sevilla, 2000, pp. 202 y 203. Por último, fue identificado como el mayor del Carmen Calzado de Carmona en HERRERA GARCÍA, Francisco Javier, "El retablo en Carmona durante la segunda mitad del siglo XVIII", en GONZÁLEZ JIMÉNEZ, Manuel (ed.): Carmona en la Edad Moderna. III congreso de Historia de Carmona. Carmona, 2003, pp. 232-233.

${ }^{6}$ El documento fue publicado en MIRA CABALLOS, E. y DE LA VILLA NOGALES, F.: Carmona en la Edad Moderna..., op. cit., pp. 134 y 135.

${ }^{7}$ HERRERA GARCÍA, Francisco Javier, QUILES GARCÍA, Fernando y SAUCEDO PRADAS, Consuelo: Carmona barroca. Panorama artístico de los siglos XVII y XVIII. Sevilla, 1997, pp. 88 y 89 .

${ }^{8}$ Otro retablo fue concedido a las hermanas de la Cruz de Fuentes de Andalucía, con sede en el antiguo convento de San Francisco, donde como ya hemos dicho se encuentra actualmente. MARTÍN RIEGO, M.: Colegio de la Sagrada Familia..., op. cit., p. 53. Sobre el convento del Carmen de Carmona remitimos a MIRA CABALLOS, E. y DE LA VILLA NOGALES, F.: Carmona en la Edad Moderna..., op. cit., pp. 265-269 y 293-294. 
En cualquier caso, además del traslado de estos retablos desde el convento del Carmen de Carmona a la localidad de Fuentes de Andalucía y al colegio sevillano, el análisis estilístico evidencia, como ya hemos apuntado, que estamos ante una obra de Francisco de Acosta "el Mayor", en lo que abundaremos más adelante.

Nuestro retablo es articulado en tres calles mediante cuatro sólidos estípites absolutamente anegados por la rocalla, de igual forma que ocurre en los casos referidos de la Fundación San Telmo de Sevilla y de San Francisco de Fuentes de Andalucía. Ya indicamos en otra ocasión que ello distingue los retablos de Francisco de Acosta de los de su padre, que solía alternar estípites tradicionales con otros recubiertos de rocalla, como ocurre en el retablo-portada de la capilla Sacramental del Salvador y en el retablo mayor de Santa Rosalía, ambos en Sevilla. En el caso de su hijo, estos soportes han perdido toda su original referencia tronco-piramidal y geométrica y están compuestos por una alborotada sucesión de golpes de talla rococó, lo que les da un sentido más cinético e inestable que los empleados con anterioridad ${ }^{9}$ (Figura 2).

Otras coincidencias de éste con los demás retablos de Francisco de Acosta son sus erizados contornos calados y el trepidante discurrir de su cornisa, la cual se contorsiona, quiebra y gira sobre sí misma en un dislocado ejercicio geométrico. Así, en el caso que nos ocupa, la cornisa en su tránsito por la calle central se retuerce y eleva, de la misma manera que ocurre, además de en los retablos referidos, en el de la capilla sacramental de la iglesia de San Jacinto de Sevilla, que atribuimos a Acosta "el Mayor"10 (Figura 3).

No obstante, son las rocallas y las figuras infantiles las que muestran una definitiva vinculación con el primogénito de Cayetano de Acosta. Las aplicaciones de formas arriñonadas gigantes, que ya ponderamos en la Fundación San Telmo y en San Francisco de Fuentes de Andalucía, vuelven a repetirse aquí de forma ostentosa, en particular en el ático. Predicamos la misma vinculación de las cabezas angélicas que tachonan el retablo y, sobre todo, del ángel que esforzadamente sostiene la repisa del manifestador del ático, el cual es idéntico a los ángeles que sostienen los estípites del retablo de San Jacinto. Por desgracia, al encontrarse tapado por la referida Sagrada Familia, no es posible analizar el relieve del ático, que parece aludir al tránsito de algún santo carmelita, al que seguramente estaría dedicado el retablo en origen (Figura 4).

En cualquier caso, este retablo, de convencional estructura tripartita, sobresale por la calidad, variedad y turgencia de su rocalla, que lo recama por completo. Su factible datación en 1772 coincide con el momento de apogeo de tal

${ }^{9}$ RECIO MIR, Álvaro: "El brillante final del barroco: el retablo rococó", en HALCÓN, Fátima, HERRERA, Francisco y RECIO, Álvaro: El retablo sevillano desde sus orígenes a la actualidad. Sevilla, 2009, pp. 364-368.

${ }^{10}$ RECIO MIR, Á.: "El retablo rococó", op. cit., p. 203. 
signo formal del rococó, justo después de la conclusión de la obra cumbre y gran modelo del estilo en Sevilla: el retablo-portada de la capilla Sacramental del Salvador. De hecho, en el referido retablo de San Jacinto, que suponemos obra de hacia 1775 , se ve ya un ligerísimo aminoramiento ornamental, que en nuestro caso mantiene toda su furibunda vigencia ${ }^{11}$.

La concatenación de motivos decorativos de esta obra es difícil de sistematizar. A los grandes riñones referidos se suman formas filamentosas muy propias de los Acosta, golpes de talla que recuerdan crestas de olas, agallonados marcos elípticos y otros detalles de vinculación fitomórfica y casi onírica. Por desgracia, la obra acusa ciertas lagunas en su aparato ornamental, lo que no le resta el más mínimo interés. La zona más alterada es la hornacina central, de la que el contrato de 1772 señalaba que habría de ser "un nicho para poner una imagen por caja de camarín"12.

Al traer a colación esta obra, no podemos dejar de insistir en la enorme riqueza del retablo sevillano rococó. Sin duda, la colosal figura de Cayetano de Acosta marcó la pauta de esta última y brillante etapa del retablo barroco sevillano, que su primogénito llevó a las últimas consecuencias y a los umbrales del neoclasicismo, que ya se anuncia al final de su carrera, como en el retablo mayor de la capilla del Palacio Arzobispal de Sevilla. Que Cayetano de Acosta apareciese en el contrato de Carmona como fiador ha sido entendido como que pudiese tener alguna responsabilidad en este ciclo de retablos de Carmona ${ }^{13}$. Por nuestra parte, pensamos, por las particulares características que ya hemos referido, que ha de ser tenido como obra del hijo, que para entonces era un artista plenamente maduro tras formarse con su padre, el cual precisamente entonces acometía su última obra, el gigantesco retablo mayor del Salvador de Sevilla ${ }^{14}$.

Por otra parte, cabe señalar que la difusión de Francisco de Acosta de la rocalla no quedaría circunscrita a Carmona ${ }^{15}$. Hay recordar en tal sentido que sustituyó a su padre al frente de la maestría mayor de talla del arzobispado hispalense en $1776^{16}$. No sabemos muy bien en qué consistía tal responsabilidad y

${ }^{11}$ Sobre la rocalla en Sevilla, el gran signo formal del rococó, remitimos a RECIO MIR, Á.: "El brillante final del barroco...", op. cit.

${ }^{12}$ MIRA CABAlloS, E. y DE LA VILlA NOGALES, F.: Carmona en la Edad Moderna..., op. cit., p. 134.

13 Así se indica en HERRERA GARCÍA, F. J.: "El retablo en Carmona...”, op. cit.

${ }^{14}$ Sobre la figura de Cayetano de Acosta resulta esencial PLEGUEZUELO HERNÁNDEZ, Alfonso: Cayetano de Acosta (1709-1778). Sevilla, 2007.

${ }^{15} \mathrm{Su}$ influencia allí se trata en HERRERA GARCÍA, F. J.: "El retablo en Carmona...", op. cit.

${ }^{16}$ ROS GONZÁLEZ, Francisco Sabas: Noticias de escultura (1781-1800). Sevilla, 1999, p. 14; y AMORES MARTÍNEZ, Francisco: "Artistas y artesanos al servicio de los arzobispos de Sevilla. Algunas noticias sobre sus maestros mayores", Anuario de historia de la Iglesia andaluza, 9, 2016, pp. 259-271, véanse en concreto las pp. 264, 265 y 271. 
de qué manera la ejerció, aunque sin duda sería cuestión interesante aquilatar la proyección de su estilo, de lo que tenemos algún ejemplo significativo documentado, como el del retablo de la capilla sacramental de Santa Bárbara de Écija ${ }^{17}$.

Sin duda, rastrear tal estela nos llevaría a encontrar nuevos retablos a él vinculables. No es nuestra intención hacer esa labor en esta ocasión, pero no queremos dejar de referir al menos otro retablo rococó, también conservado en blanco, de singular factura: el de la Virgen con el Niño de la parroquia de la Consolación de El Pedroso, Sevilla ${ }^{18}$. Es una obra de menor envergadura que la de la capilla del colegio Sagrada Familia de Sevilla, pero de las mismas características técnicas, estilísticas y cronológicas (Figura 5).

Tanto este último ejemplo, como, sobre todo, el que hemos analizado en esta ocasión, evidencian, una vez más, la referida riqueza del retablo sevillano rococó y cómo la rocalla se hizo dueña absoluta de las ensambladuras levantadas en gran parte de la segunda mitad del siglo XVIII. El ostentoso triunfo de la rocalla sobre unas estructuras que apenas se renovaron por entonces señala la crucial significación del ornamento en este ámbito artístico, que sin duda merece seguir siendo investigado en futuros estudios.

Fecha de recepción: 16 de noviembre de 2016

Fecha de aceptación: 4 de enero de 2017

${ }^{17}$ HERRERA GARCÍA, Francisco Javier: "Écija como centro artístico. Los tallistas del siglo XVIII" y FERNÁNDEZ MARTÍN, María Mercedes: "José Araujo y el retablo de la capilla sacramental de Santa Bárbara de Écija", ambos en II congreso de historia de Écija, Écija en el siglo XVIII. Écija, 1995, pp. 338 y 348 respectivamente.

18 Agradecemos la fotografía del mismo a nuestro colega Antonio J. Santos Márquez. 


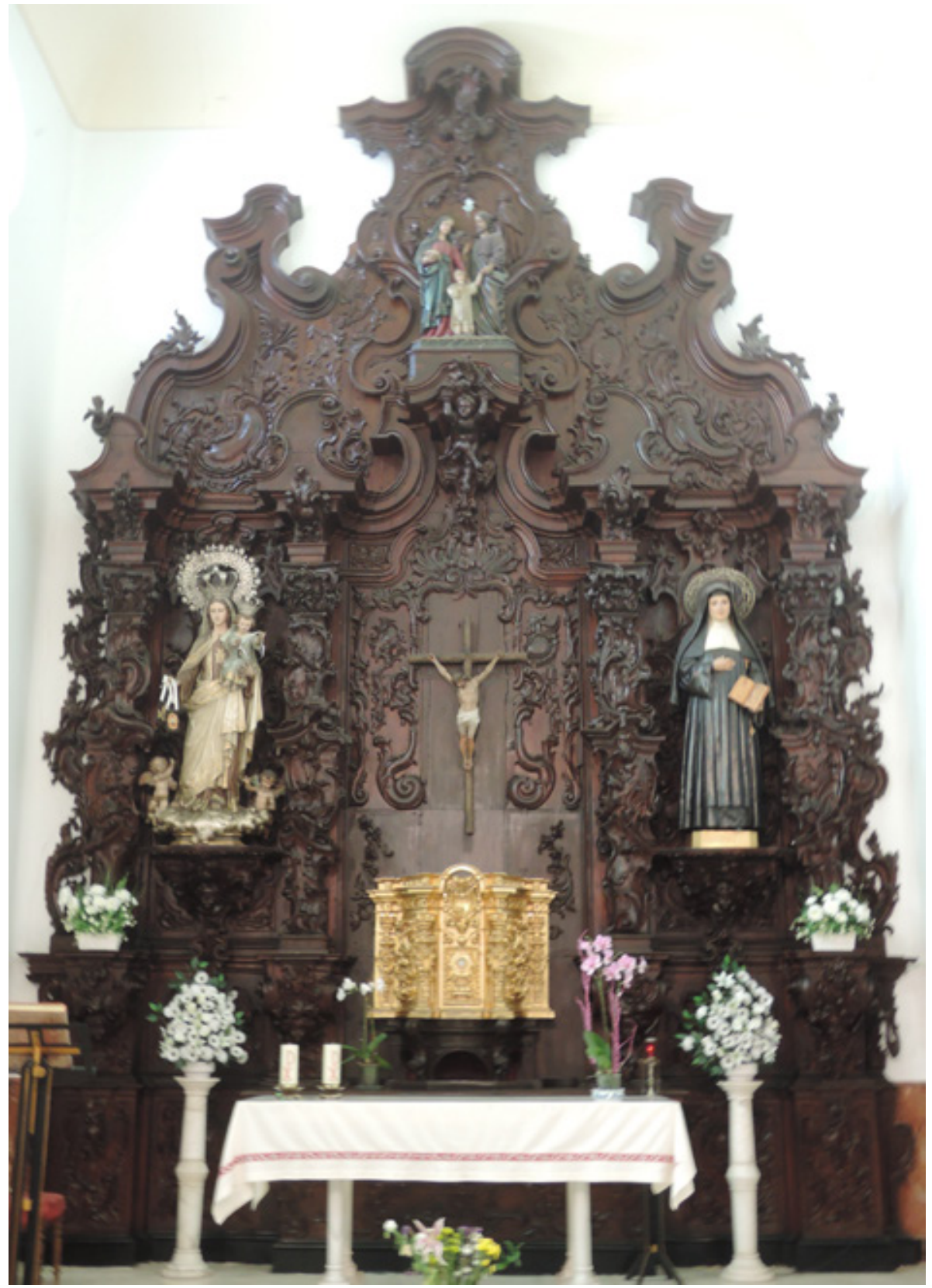

Figura 1. Francisco de Acosta "el Mayor", Retablo mayor, 1772, capilla del colegio Sagrada Familia, Sevilla. 


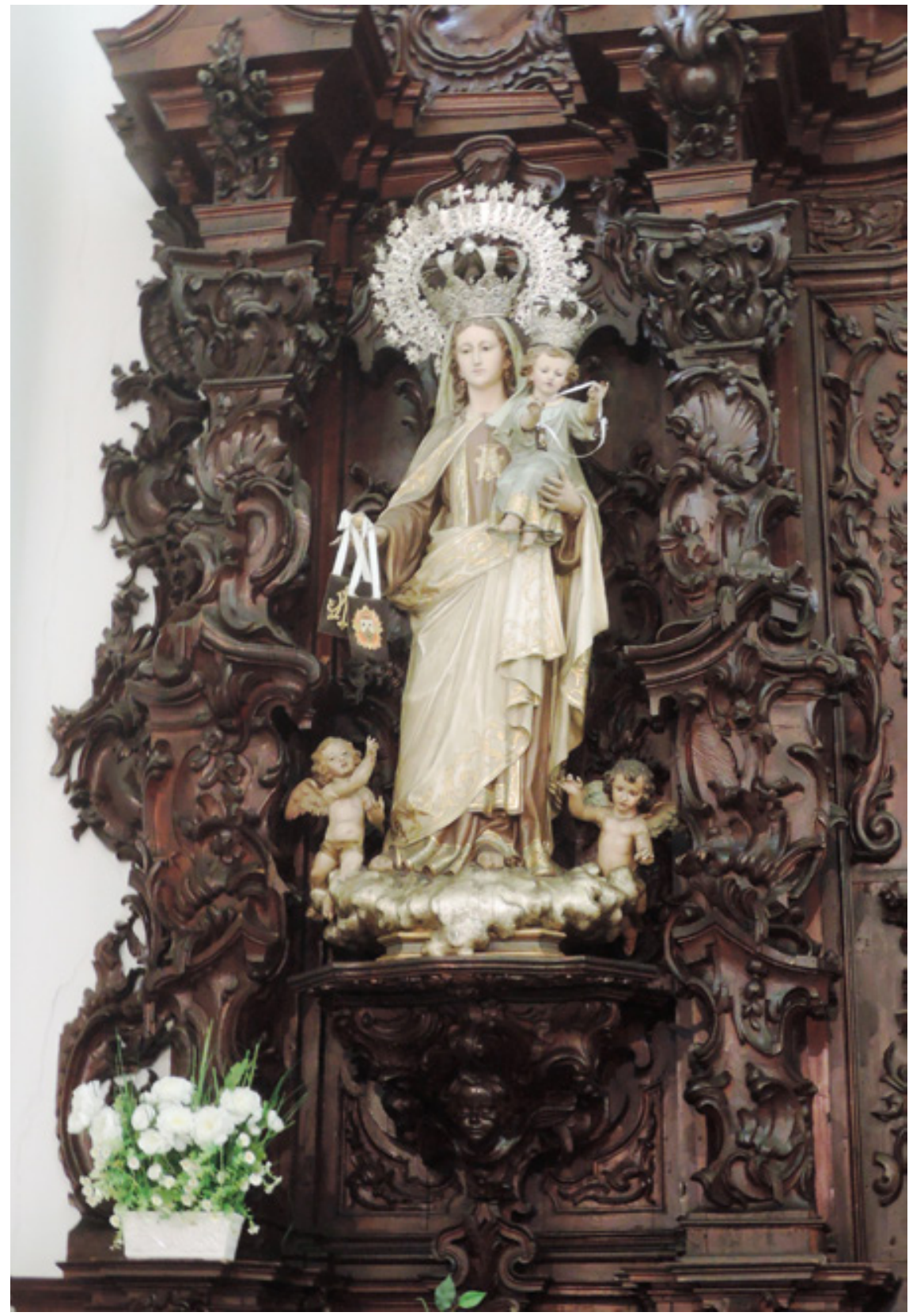

Figura 2. Francisco de Acosta "el Mayor", Retablo mayor (detalle), 1772, capilla del colegio Sagrada Familia, Sevilla. 


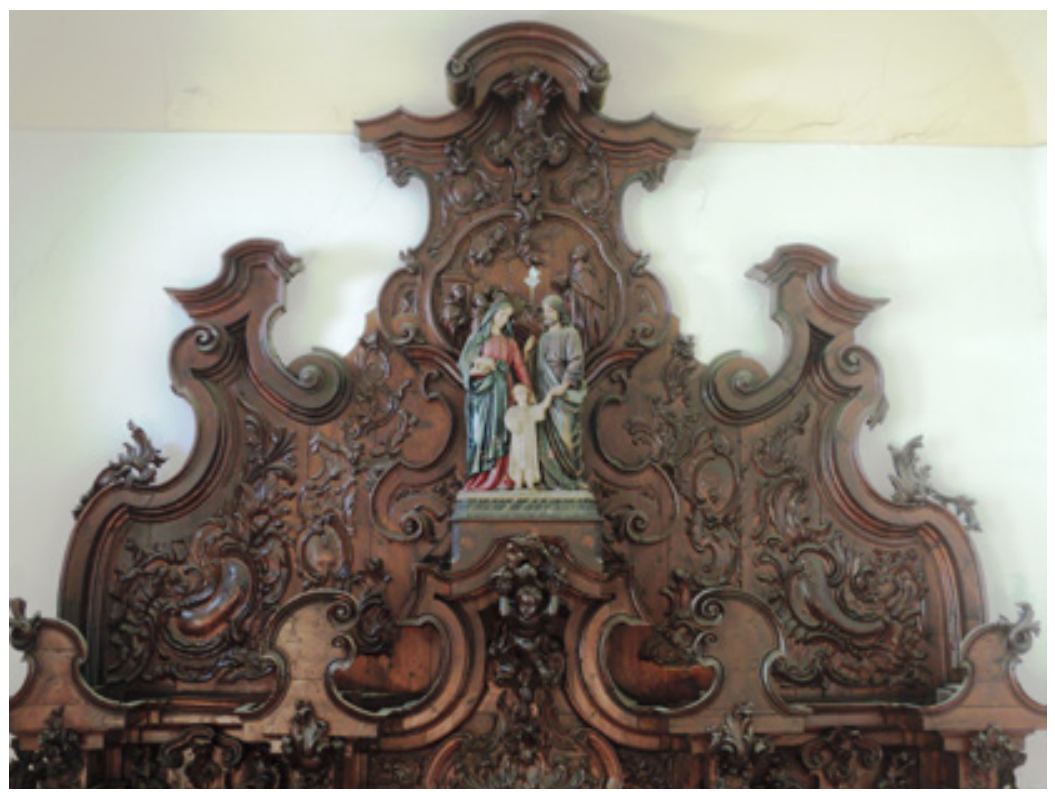

Figura 3. Francisco de Acosta "el Mayor", Retablo mayor (detalle), 1772, capilla del colegio Sagrada Familia, Sevilla.

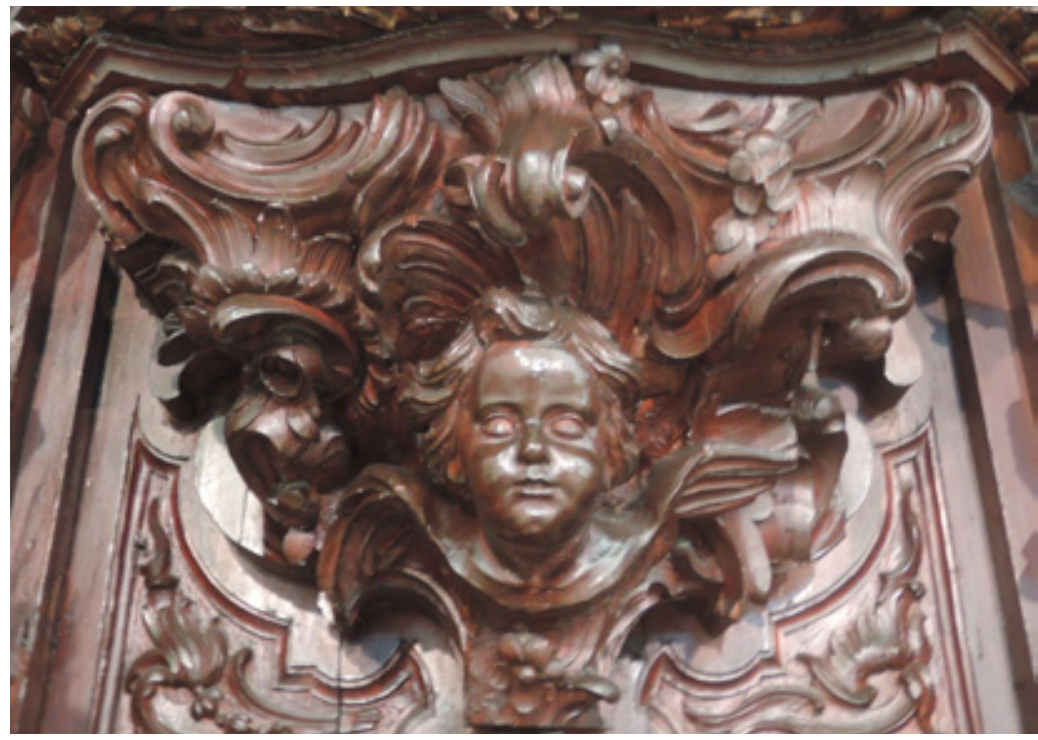

Figura 4. Francisco de Acosta "el Mayor", Retablo mayor (detalle), 1772, capilla del colegio Sagrada Familia, Sevilla. 


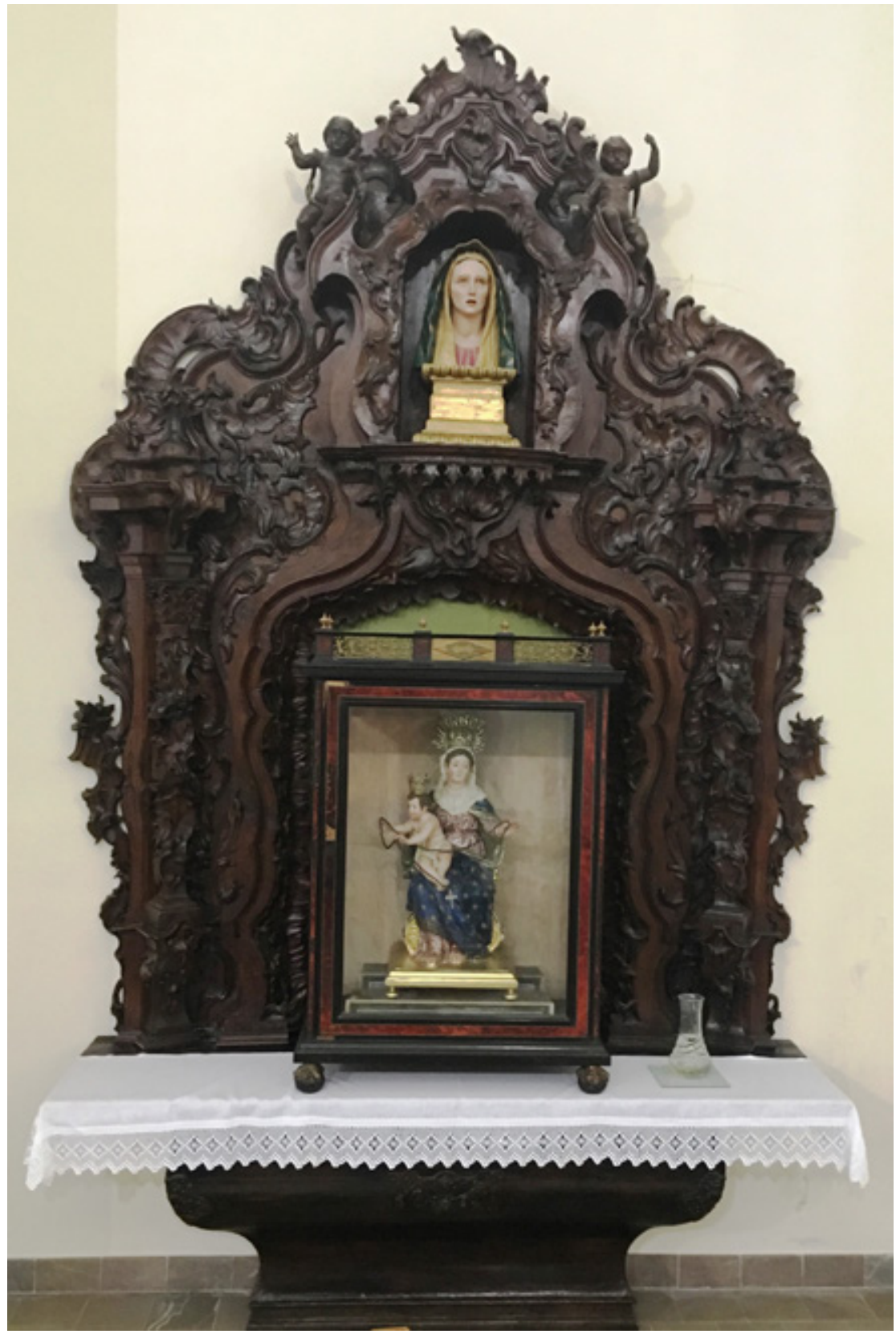

Figura 5. Anónimo, Retablo de la Virgen con el Niño, hacia 1770, parroquia de Nuestra Señora de la Consolación, El Pedroso (Sevilla). 